\title{
A NOVEL METHOD FOR WATER AND WATER CANAL EXTRACTION FROM LANDSAT-8 OLI IMAGERY
}

\author{
S.Lenin Kumar Reddy ${ }^{1}{ }^{*}$, C.V.Rao ${ }^{1}$, P. Rajesh $\mathrm{Kumar}^{2}$, R.V.G.Anjaneyulu ${ }^{1}$, B.Gopala Krishna ${ }^{1}$ \\ ${ }^{1}$ G\&SPG, DPPA\&WAA, National Remote Sensing Centre, India - leninkumar438@gmail.com,rao_cv@nrsc.gov.in) \\ 2 Dept.of Electronics \& communication engg., Andhra University, India - rajeshauce@ gmail.com
}

Commission V, SS : Natural Resources Management

Key words:Water canal extraction, Modified Normalised Difference Water Index (MNDWI), MNDWI-2, NDVI

\begin{abstract}
:
Constituents of hydrologic network, River and water canals play a key role in Agriculture for cultivation, Industrial activities and urban planning. Remote sensing images can be effectively used for water canal extraction, which significantly improves the accuracy and reduces the cost involved in mapping using conventional means. Using remote sensing data, the water Index (WI), Normalized Difference Water Index (NDWI) and Modified NDWI (MNDWI) are used in extracting the water bodies. These techniques are aimed at water body detection and need to be complemented with additional information for the extraction of complete water canal networks. The proposed index MNDWI-2 is able to find the water bodies and water canals as well from the Landsat-8 OLI imagery and is based on the SWIR2 band. In this paper, we use Level-1 precision terrain corrected OLI imagery at 30 meter spatial resolution. The proposed MNDWI-2 index is derived using SWIR2 (B7) band and Green (B3) band. The usage of SWIR2 band over SWIR1 results in very low reflectance values for water features, detection of shallow water and delineation of water features with rest of the features in the image. The computed MNDWI-2 index values are threshold by making the values greater than zero as 1 and less than zero as zero. The binarised values of 1 represent the water bodies and 0 represent the non-water body. This normalized index detects the water bodies and canals as well as vegetation which appears in the form of noise. The vegetation from the MNDWI-2 image is removed by using the NDVI index, which is calculated using the Top of Atmosphere (TOA) corrected images. The paper presents the results of water canal extraction in comparison with the major available indexes. The proposed index can be used for water and water canal extraction from L8 OLI imagery, and can be extended for other high resolution sensors.
\end{abstract}

\section{INTRODUCTION}

Water is one of the most essential resources for human life and covers about 70 percent of the earth. Hydrological features which include rivers, lakes and water canals, are crucial for monitoring the flood risks, water cycles used for predicting geomorphological changes (Liu and Wang, 2008) play an important role in irrigation, industrial and urban planning (Prasad et. al., 2009/3). Since last 3 decades, water detection from the Remote Sensing images are being widely used to reduce the cost and time. Standard approaches rely heavily on the manual delineation of water bodies from remote sensing images (Schumann et al., 2008). The detection of water \& water canals is an involved problem for researchers in remote sensing.

For water body detection and change detection, many remote sensing studies use the Landsat imagery because of its temporal coverage. Several indexes were developed for Water body detection and Water Index (WI) (McFeeter's, 1996) (Xu, 2006) using the OLI data. The Landsat-8 Operational Land Imagery (OLI) contains 8 multispectral bands with a spatial resolutions of 30-meter and contain one panchromatic band (B8) with 15-meter with a radiometric resolution of 16-bit as shown in Table-1.
The existing approaches used for water body detection are Water Ratio Index (WRI) (Shen and $\mathrm{Li}, 2010$ ), Normalized Difference Water Index (NDWI) (McFeeter's, 1996) and Modified NDWI (MNDWI) (Xu, 2006). NDWI (McFeeter's) index was able to extract water bodies and suppressing the vegetation and soil features, however, it cannot fully distinguish the built-up features from the water bodies. MNDWI (Xu's) was introduced for suppressing the built-up features in addition to vegetation and soil features. MNDWI and NDWI indexes, (Li et al., 2013) are used to extract water bodies from the various optical remote sensing sensors.

The primary WI are given by McFeeter's and Xu's as

$$
\begin{aligned}
& N D W I=\frac{\text { Green }-N I R}{\text { Green }+N I R} \\
& M N D W I=\frac{\text { Green-SWIR1 }}{\text { Green }+ \text { SWIR1 }}
\end{aligned}
$$

\footnotetext{
* Corresponding author
} 


\begin{tabular}{|l|c|c|}
\hline \multicolumn{1}{|c|}{ Band Name } & $\begin{array}{c}\text { Wavelength } \\
(\mu \mathrm{m})\end{array}$ & $\begin{array}{c}\text { Spatial } \\
\text { Resolution }(\mathrm{m})\end{array}$ \\
\hline B1 - aerosol & $0.43-0.45$ & 30 \\
\hline B2 - Blue & $0.45-0.51$ & 30 \\
\hline B3 - Green & $0.53-0.59$ & 30 \\
\hline B4 - Red & $0.64-0.67$ & 30 \\
\hline B5 - NIR & $0.85-0.88$ & 30 \\
\hline B6 - SWIR 1 & $1.57-1.65$ & 30 \\
\hline B7 - SWIR 2 & $2.11-2.29$ & 30 \\
\hline B8 - Panchromatic & $0.50-0.68$ & 15 \\
\hline B9 - Cirrus & $1.32-1.36$ & 30 \\
\hline
\end{tabular}

Table 1: LANDSAT-8 (OLI) Sensors and Band Names

$$
W R I=\frac{\text { Green }+ \text { Red }}{\mathrm{NIR}+S W I R 2}
$$

Du et al., given a study of water body delineation and mapping using the bands band3 and band6 (Du et al., 2014). These strategies were based on the fact that the reflected radiance of water within the SWIR band is below that of other objects like vegetation, buildings, bare soil, and roads. Automatic water extraction index (AWEI) (Feyisa et al., 2014) introduced by addition and subtraction of bands with the coefficients. AWEI $I_{n h}$ is suitable for where the shadows are not present, and $\mathrm{AWEI}_{\mathrm{sh}}$ is introduced to suppress the shadows and dark surfaces in an image.

$$
\begin{aligned}
& \quad A W E I_{n s h}=4 *(B 2-B 5)-(0.25 * B 4 \\
& +2.75 * B 7) \\
& A W E I_{s h}=B 1+(0.25 * B 2)-1.5 *(B 4+B 5) \\
& -0.25 * B 7)
\end{aligned}
$$

A method by (D. Nguyen, 2012) for water bodies extraction based on the spectral pattern of water in 4 bands green, red, NIR and SWIR and level slicing into water using different threshold values for the SWIR band from Landsat $5 \mathrm{TM}$ and SPOT $5 \mathrm{HRG}$ images. Water indexes (WI) are the most suitable option for extracting the water bodies in optical images than single-band strategies. By varying the threshold parameter these indexes are getting with the roads and urban. These indexes are designed for water bodies and are not effective to find the water canals due to the artificial canals (constructed with the concrete) using the remote sensing images.

From the NDWI indexes, we observe that, it enhances water bodies by the two different bands with their different wavelengths and suppress the most of other features. With the increase of wavelength (0.43(B1)-2.29 (B7)), water has a low reflectance. From the bands NIR (B5) onwards, water has a steadily increase in absorption capability, unlike vegetation. Therefore, NDWI will effectively extract water bodies by distinguishing the water and vegetation. Hence, McFeeter's NDWI and Xu's NDWI have been used as the primary methods, which is effective in extracting the water-bodies and ineffective in getting the canals.
A modified water body extraction method combining several current methods to extract the water \& water canal using the OLI imagery is proposed in this study. It is demonstrated that this method can extract small water bodies, such as lakes and artificial canals.

\section{PROPOSED METHOD}

\subsection{Study area}

The study area selected, is having river (krishna basin), lakes, reservoir (Paleru), located near the city of Khammam and canal (Nagaruna Sagar left canal branch) refer Figure-3. The OLI images with L1TP (Level 1 Terrain Precision) processing were used as the study areas, (scene-1) acquired on $3^{\text {rd }}$, May, 2017, with Scene ID : LC81430482017123LGN00 and another data (scene-2) acquired on 24, April 2017 with Scene ID : LC81440492017114LGN00 are used. Scene-3 (27-042018) with Scene ID is LC81440492018117LGN00. The 16-Bit radiometric resolution of data can effectively avoid grayscale over saturation in extreme dark region and facilitate discriminating subtle features of water bodies with extremely low reflectivity.

\subsection{Data pre-processing}

The indexes mentioned earlier, were calculated by the TOA reflectance corrected images, instead of quantized calibrated pixel values (Digital Number). In the proposed method, NDVI is also used, which also requires the TOA correction for the associated images. The conversion of $\mathrm{DN}$ to reflectance, is from Chander $\mathrm{G}$ et al., (Chander G, 2009).

Reflectance L, is obtained from the quantized calibrated pixel values (DN) $\left(Q_{\text {cal }}\right)$ as follows:

$$
L=M Q_{c a l}+A
$$

where $\mathrm{M}$ is the band (selected) multiplicative rescaling factor and $\mathrm{A}$ is the band (selected) additive rescaling factor. The parameters $\mathrm{M}$ and $\mathrm{A}$ are used from the OLI meta-data file.

\subsection{MNDWI-2}

Many algorithms were developed to separate water and non-water body ( $\mathrm{Li}$ et al., 2013) features, based on the spectral features of the different targets like water, vegetation, land etc. In this paper a new method with the index (MNDWI-2) is proposed to extract all the water bodies as well as the water canals based on the indices MNDWI-2 and NDVI.

In this study, Green and SWIR2 bands were used for the computation of MNDWI2 to get the water \& water canals extraction from Xu's NDWI models. These bands were chosen based on the water and water canal and having high contrast with other features reflectance ranges. Water has the high reflectance in lower wavelengths $(0.45-0.51 \mu \mathrm{m}, 0.53-0.59 \mu \mathrm{m})$ (Blue and Green) bands and has low in higher wavelengths $(0.85$ - 
$2.29 \mu m$ ) i.e., NIR, SWIR1 and SWIR2, hence it makes easy to differentiate water bodies from other land mass in the remote sensing images. In the visible part of the spectrum, the albedo of water bodies is lower than $10 \%$ and it continues to diminish gradually with the increase of wavelength.

The water canal has high reflectance due to the construction of gravel or concrete. The spectral reflectance of water and canal is shownfigure-1 along with other land features. In SWIR2 band, clear waterbodies has very low reflectance and water canal has a little bit high reflectance and less when compared to other features like builtup, vegetation and roads as shown in figure-1.

From the figure-1, in Green (B3) band, the reflectance of the roads and vegetation is lower than the water canal. In contrast, in SWIR2 (B7), the water canal has low reflectance than roads, vegetation and built-up. In NIR (B5), the canal has high reflectance than roads and in SWIR1 (B6), almost has the same reflectance. Due to this, NIR and SWIR1 bands based indexes are unable to separate from builtup, water $(\mathrm{Xu}, 2006)$ and water canal. The proposed method with index MNDWI-2 were computed by taking the differences between the bands of B3 and B7, which gives the positive values for the water \& water canal and negative values for the builtup and roads. This index is able to separate the water canal from roads and builtup, and also able to extract the shallow water finely as shown in figure-7.

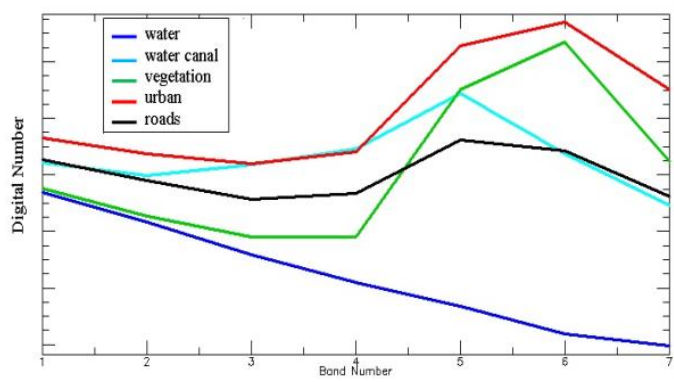

Figure 1: Spectral Curves of various land feature

$$
M N D W I 2=\frac{\text { Green }-S W I R 2}{\text { Green }+S W I R 2}
$$

To extract the water and as well as canal, the threshold value is $>0$ (all positive values) as standard value for the MNDWI2 index. In the results obtained using MNDWI2, we observe that the water bodies and canals are present along with the vegetation. Water bodies and water canals were seperated from vegetation by using NDVI, which is calculated using the bands red and NIR, the corresponding equation is:

$$
N D V I=\frac{R e d-N I R}{R e d+N I R}
$$

The NDVI value greater than 0.25 is considered as vegetation in the proposed method. The amount of vegetation presented in the MNDWI2 is removed wherever the NDVI vegetation value coincides with the MNDWI2 value, to extract the water bodies as well as water (artificial) canals. The block diagram of proposed method is shown in figure-2. The pseudo code of the proposed method is shown below. The experimental results show the ability of the proposed method.

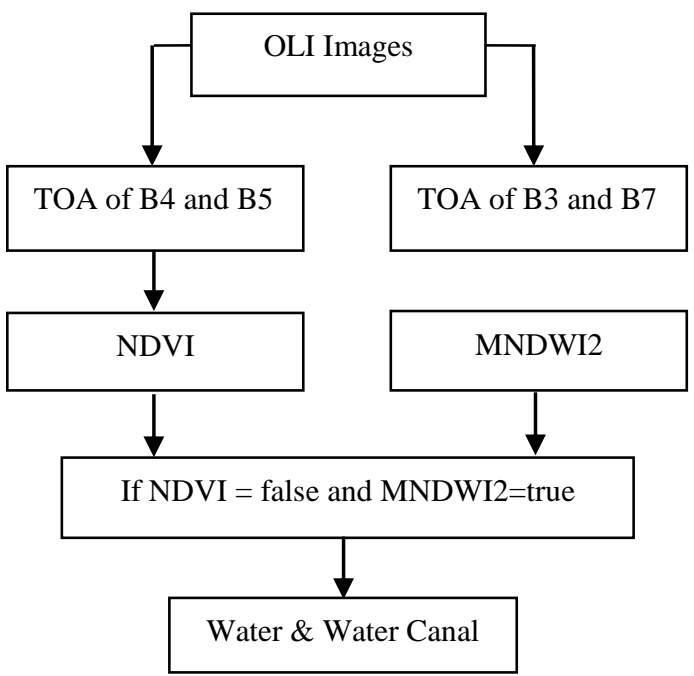

Figure 2: Block diagram of MNDWI2

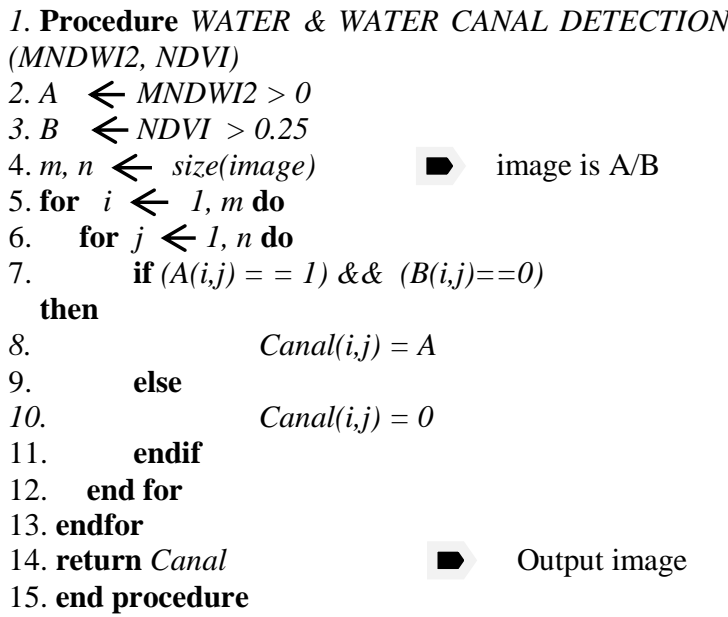

\section{EXPERIMENTAL RESULTS}

In this study, the proposed method is performed on the L1TP corrected OLI data with the 30-meter spatial resolution. The water indices MNDWI, AWEInsh and $\mathrm{AWEI}_{\mathrm{sh}}$ were calculated to evaluate their performances for the extraction of water bodies and water canal. In this case, all these indexes are thresholded with the all positive values $(>0)$, for water and as well as water canal extraction. By varying the threshold values of their indexes canals are getting extracted along with urban features. By using the proposed method with the index MNDWI2 > 0 for all the presented scenes, the water \& water canals are extracted for the case study images. The corresponding results are shown.

Scene-1 (LC81430482017123LGN00) of the sub figure shown in figure-3 represents the B432 layer-stacked natural color image which consists the river, reservoir and canal. As shown in figure-4, MNDWI is able to 
extract the water bodies and indexes $\mathrm{AWEI}_{\mathrm{nsh}}$ and AWEIsh are also able to extract the water bodies but not water canals as in figures-5 and 6 . The proposed method with the index MNDWI2 is able to extract the water bodies and water canals as shown in figures-7 (8\&10), 13, 14 and 15. From figure-7, we can observe that, the river shallow water also extracted by the proposed method. The reference data of water layer used was from Global Surface Water Explorer [Jean-Franois Pekel, 2016] is 32 years of aggregated water bodies and showing the maximum level water extent including the maximum extent of water for the entire period is shown in figure-9. And also performed on the Scene-2 ( LC81440492017114LGN00) of the sub scenes are shown in Figure-13 in different conditions like hilly terrain, plain terrain and urban terrain (figure-10) with water bodies of artificial canal and natural canal.

From the results we observe that, the pure water-bodies are extracted efficiently and able to remove the pure vegetation. The threshold value for vegetation in NDVI index is $>0.25$ as standard value for all the test case images. The proposed method is efficiently suppressing the built up and roads from the canals. And also water canals (natural \& artificial) are extracted wherever the water is present. The discontinuities in the water canals are due to water not being present and also width of canal is less than the spatial resolution.

We know that SWIR band region is sensitive to moisture content in the soil as well as in crop canopy. i.e., sensitive to soil moisture of top 1 to $2 \mathrm{~cm}$. When the crop is grown up, SWIR (sensitive to leaf moisture) response is only from the canopy not from the underlying soil i.e., SWIR can't penetrate through leaves. Wet soil has very low positive values in the proposed index of MNDWI2 ( $\leq 0.03$ ) which represents the soil wetness only. This is one of the limitation of proposed method. Wet soil is also getting detected as the water body when MNDWI $2 \geq 0$ as shown in figure-14-b of sub scene-2. From the Section2.3 , this can removed by the observation in MNDWI2 $\geq$ 0.03 as shown in figure-14-c.

Also we observed a change detection in the images of two consecutive years data sets which are Scene-2 (2404-2017) and Scene-3 (27-04-2018) with scene id is LC81440492018117LGN00. The corresponding results of Scene-2 and Scene-3 of sub scenes are shown in figure-15.

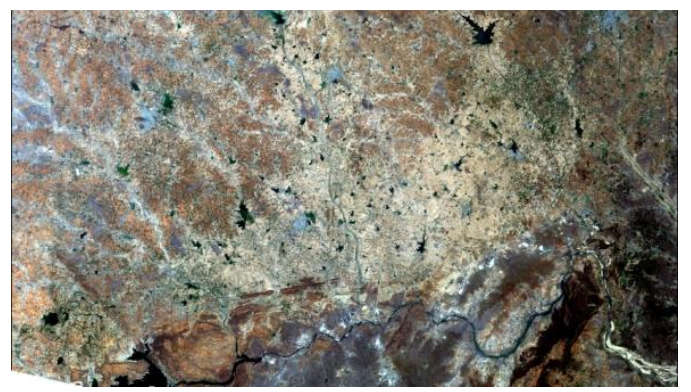

Figure 3: OLI 432-natural image(30m) (Krishna river with left canal)

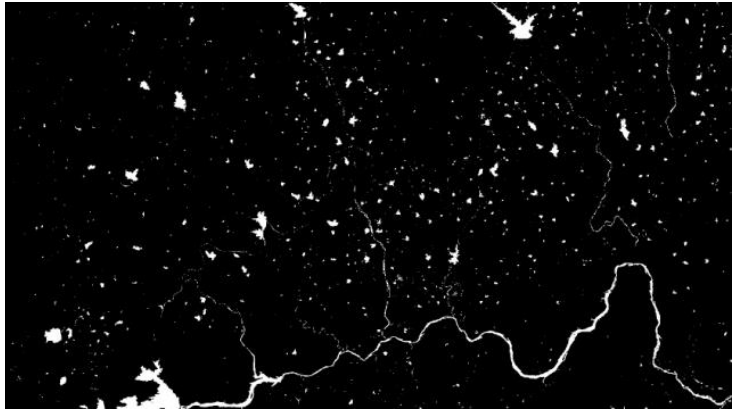

Figure 4: MNDWI (30m)

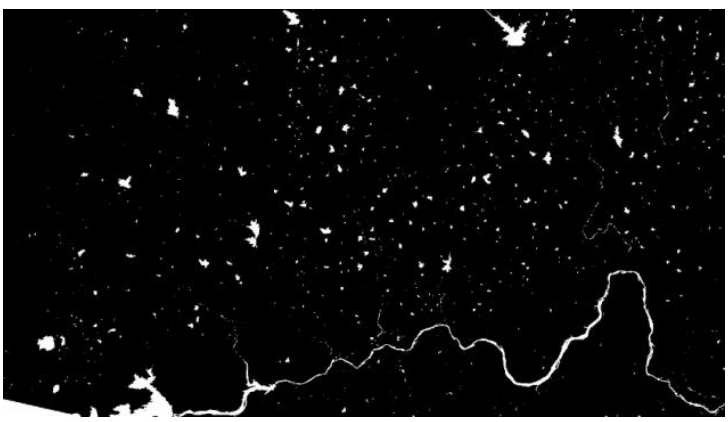

Figure 5: AWEI (30m)

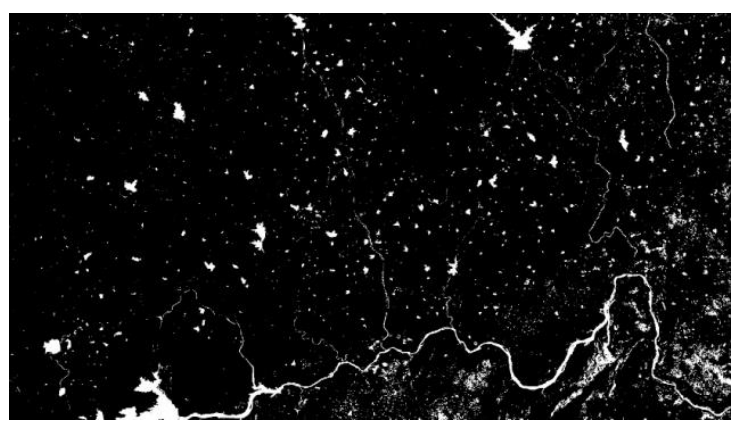

Figure 6: AWEIsh (30m)

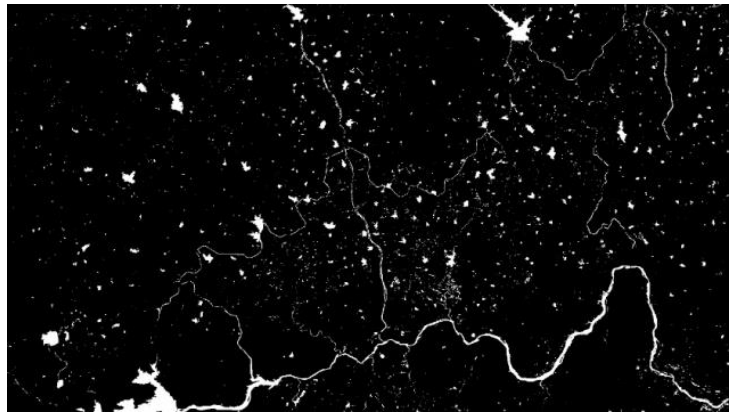

Figure 7: Proposed (30m) 


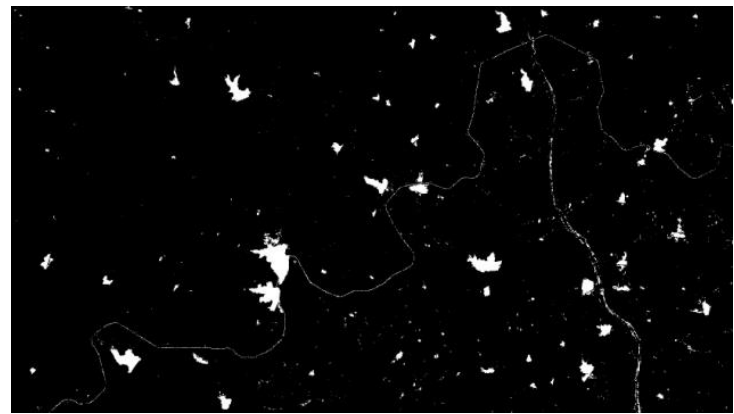

Figure 8: Nagarjuna sagar left canal branch from figure-7

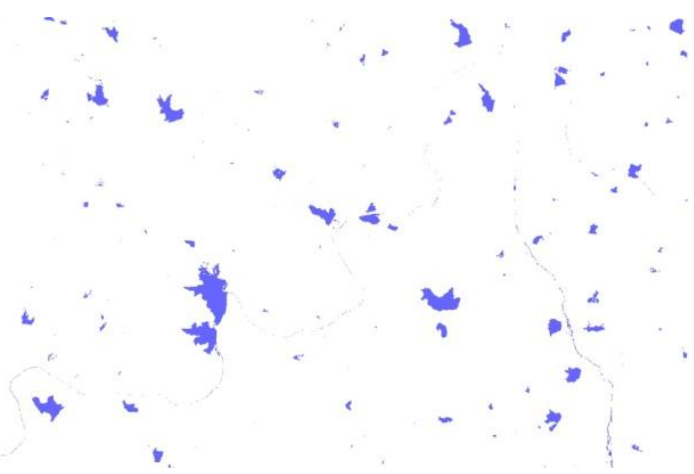

Figure 9: Reference image (Source: EC JRC/Google)

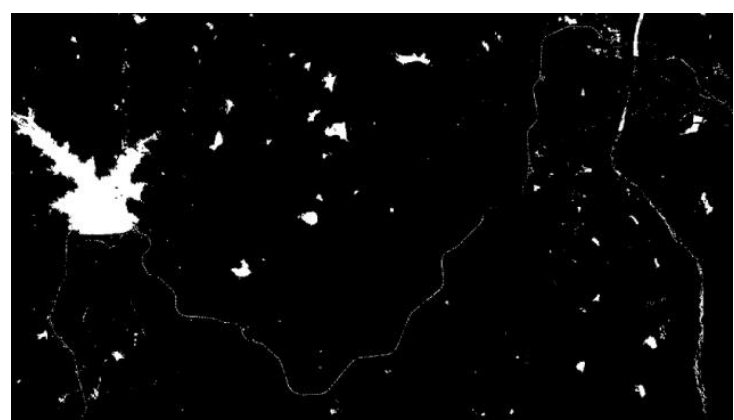

Figure 10: Paleru reservoir with canal from figure-7

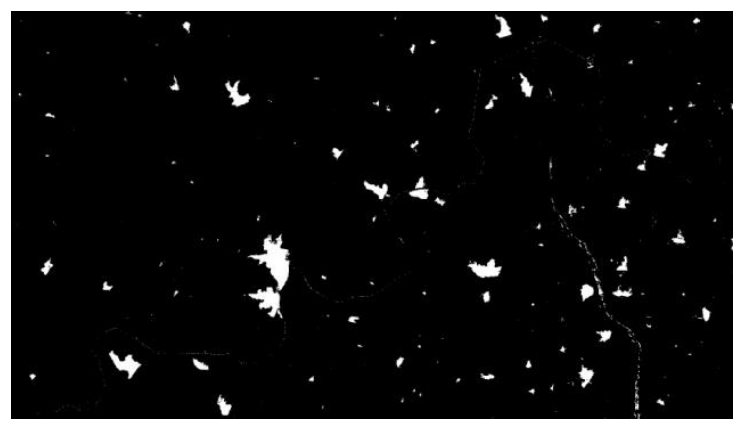

Figure 11: MNDWI Nagarjuna sagar left canal branch

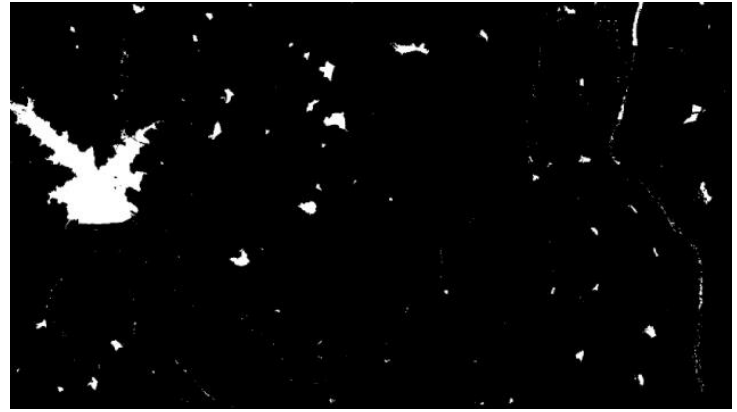

Figure 12: MNDWI Paleru reservoir with canal

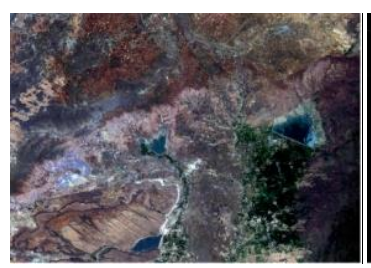

(a)

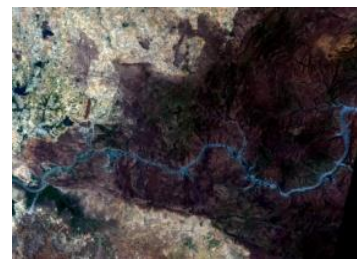

(c)

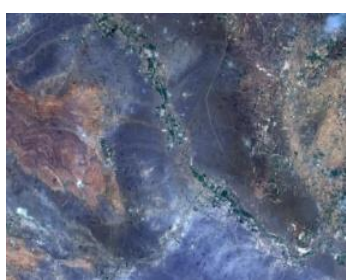

(e)

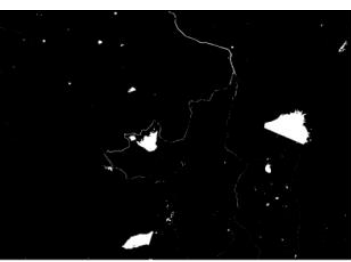

(b)

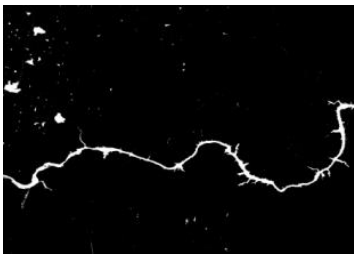

(d)

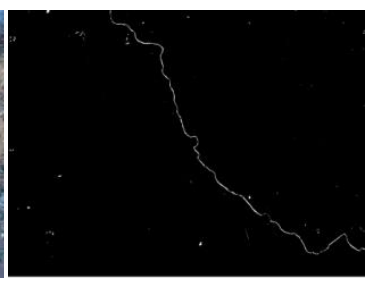

(f)
Figure 13: (a),(c),(e) are sub scenes of Scene-2 (b), (d), (f) proposed method

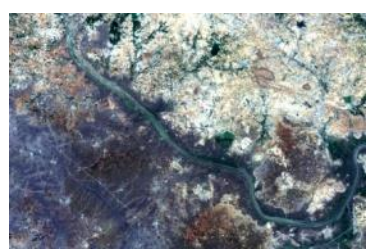

(a)

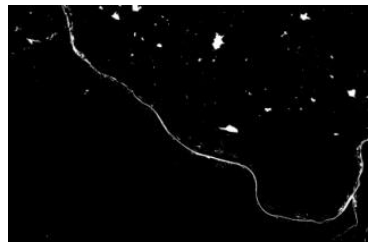

(c)

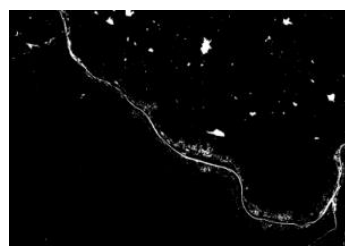

(b)

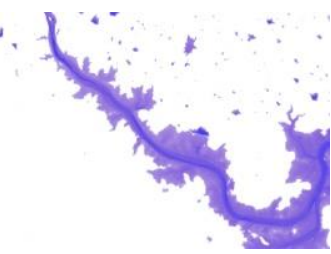

(d)
Figure 14: (a) Sub scenes of Scene-2 (b)proposed method: river bank with wet soil (c) river bank removed wet soil $(\leq 0.03)$ (d) Reference image of occurrence 


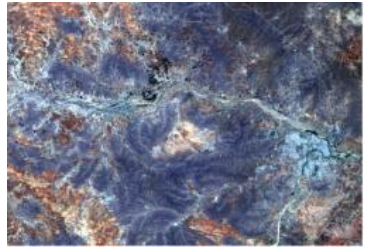

(a)

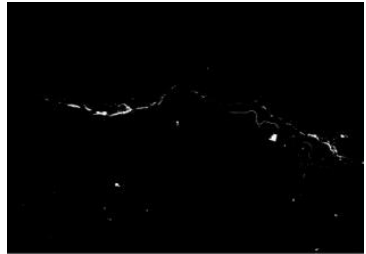

(c)

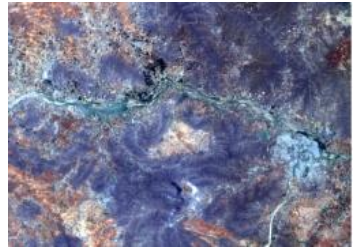

(b)

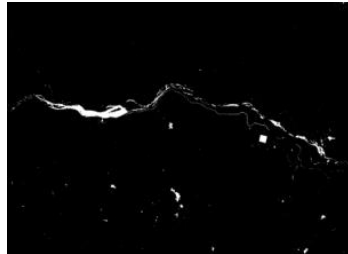

(d)
Figure 15: (a) Sub scene of Scene-2 (24-04-2017) (b) Sub scene of Scene-3 (27-04-2018) (c) proposed (24-042017) (d) proposed (27-04-2018)

\section{CONCLUSIONS}

In this study, we presented, water and water canal extraction from OLI images using with different NDWI models. The proposed method, MNDWI2 efficiently extracting the water and water (artificial) canals. The results also demonstrate that the proposed model based on the B3 (Green) and the B7 (SWIR2) bands of the OLI data is the best index for the extraction of water body and water canal. The advantages of each water body extraction method are utilized effectively in combination to achieve accuracy in the extraction which is better than the result of the individual method. In addition, water canal information is also obtained by the modified method.

In view of the accurate extraction of rivers, lakes and canal, this study proves an automatic water body and canal extraction model by modifying the proven automatic water extraction methods NDWI and MNDWI. Water bodies associated with artificial canals of the Krishna River and the river tributaries have been extracted successfully by using proposed method.

Limitations of the modified method are associated with the fact that cropland water with spectral characteristics extremely similar (mixed pixels) to those of water cannot be eliminated completely.

\section{ACKNOWLEDGEMENTS}

We wish to express our sincere gratitude to Dr.Vinod Bothale, Deputy Director, DPPA \& WAA and Dr. Shantanu Choudhary, Director, National Remote Sensing Centre for their encouragement and guidance in bringing out this publication.

\section{REFERENCES}

Chander G, Markham B L, H. D. L., 2009. Summary of current radiometric calibration coefficients for landsat MSS, TM, ETM+, and EO1ALI sensors. Remote Sens. Environ. (113), pp. 893-903.
D. Nguyen, D., 2012. Water body extraction from multi spectral image by spectral pattern analysis. ISPRS International Archives of the Photogrammetry, Remote Sensing and Spatial Information Sciences XXXIX-B8, pp. 181-186.

Du, Z., Li, W., Zhou, D., Tian, L., Ling, F., Wang, H., Gui, Y. and Sun, B., 2014. Analysis of landsat-8 OLI imagery for land surface water mapping. Remote Sensing Letters 5(7), pp. 672-681.

Feyisa, G. L., Meilby, H., Fensholt, R. and Proud, S., 2014. Automated water extraction index: A new technique for surface water mapping using landsat imagery. 140, pp. 23-35.

Jean-Franois Pekel, Andrew Cottam, N. G. A. S. B., 2016. High-resolution mapping of global surface water and its long-term changes. Nature 540, pp. 418-422.

Li, W., Du, Z., Ling, F., Zhou, D., Wang, H., Gui, Y., Sun, B. and Zhang, X., 2013. A comparison of land surface water mapping using the normalized difference water index from TM, ETM+ and ALI. Remote Sensing 5(11), pp. 5530-5549.

Li, Y., Gong, X., Guo, Z., Xu, K., Hu, D. and Zhou, H., 2016. An index and approach for water extraction using landsat-8 OLI data. International Journal of Remote Sensing 37(16), pp. 3611-3635.

Liu, H. and Wang, L., 2008. Mapping detention basins and deriving their spatial attributes from airborne lidar data for hydrological applications. 22, pp. $2358-2369$.

McFeeters, S. K., 1996. The use of the normalized difference water index (ndwi) in the delineation of open water features. International Journal of Remote Sensing 17(7), pp. 1425-1432.

Prasad, P. R. C., KS Rajan, V. B. and Dutt, C., 2009/3. Is rapid urbanization leading to loss of water bodies. $J$. of Spatial Science 2(2), pp. 43-52.

Schumann, G., P. Matgen, M. C., A. Black, L. H. and Pfister, L., 2008. Comparison of remotely sensed water stages from lidar, topographic contours and srtm. ISPRS J. Photogramm. Remote Sens. 63(3), pp. 283-296.

Shen, L. and Li, C., 2010. Water body extraction from landsat etm+ imagery using adaboost algorithm. In: 2010 18th International Conference on Geoinformatics, pp. 14.

$\mathrm{Xu}$, H., 2006. Modification of normalised difference water index (ndwi) to enhance open water features in remotely sensed imagery. International Journal of Remote Sensing 27(14), pp. 3025-3033. 